\title{
El Pico de la Mora (Peñafiel, Valladolid). Un nuevo asentamiento amurallado del Calcolítico Inicial normeseteño*
}

\author{
El Pico de la Mora (Peñafiel, Valladolid). A new Early Copper Age walled settlement in the \\ Spanish Northern Meseta
}

Rodrigo Villalobos García ${ }^{\mathrm{a}}$ y José Antonio Rodríguez-Marcos ${ }^{\mathrm{b}}$

\begin{abstract}
RESUMEN
Se presentan los resultados de la reciente intervención desarrollada en el yacimiento calcolítico de El Pico de la Mora (Peñafiel, Valladolid). Éste es un pequeño asentamiento de 0,5 ha el cual ocupa el extremo de un espigón de páramo y su peculiaridad consiste en que cuenta con una muralla de $100 \mathrm{~m}$ de longitud defendiendo su flanco más desprotegido. La excavación de la misma ha servido para identificar una compleja estructura arquitectónica pétrea - con basamento, lienzos, relleno y contrafuerte - que ha sido fechada por radiocarbono en el periodo $c a$. 2900-2650 cal a. C. Esto convierte a El Pico de la Mora en el más antiguo asentamiento amurallado del valle medio del Duero y uno de los más septentrionales de todo el Calcolítico peninsular.
\end{abstract}

\begin{abstract}
El Pico de la Mora (Peñafiel, Valladolid) is a small settlement $(0.5 \mathrm{ha})$ located at the edge of a narrow promontory with a stone wall $100 \mathrm{~m}$ in length protecting its weakest flank. Excavation of the wall has shown to be a complex architectural structure built with limestone blocks and composed of a foundation, two facings, a fill and a buttress. It has been radiocarbon dated to ca. 2900-2650 cal BCE. This makes El Pico de la Mora the oldest walled settlement of the middle Douro Valley and one of the northernmost Iberian Copper Age walled settlements.
\end{abstract}

Palabras clave: Asentamiento amurallado; Calcolítico Inicial; Campaniforme; Meseta Norte española; Datación radiocarbónica.
Key words: Walled settlement; Early Copper Age; Bell Beaker; Spanish Northern Meseta; Radiocarbon dating.

\section{INTRODUCCIÓN}

Los asentamientos amurallados han sido una característica definitoria de las Primeras Edades del Metal en la Península Ibérica desde la publicación de Los Millares y otros asentamientos del Sureste por parte de los hermanos Siret (Siret y Siret 1890). Más de un siglo después, se han identificado yacimientos de este tipo, adscribibles a la Edad del Cobre, en buena parte del territorio peninsular (Jorge 1994), que suelen presentarse como un elemento especialmente relevante a la hora de interpretar los procesos de aparición de la complejidad social (e.g., Lillios 1995; Díaz-del-Río y García Sanjuán 2006; Chapman 2008).

El registro arqueológico del interior peninsular se ha mostrado bastante parco en estos lugares amurallados calcolíticos. La Meseta Sur ha acogido varios recintos fosados (Díaz-del-Río 2003) pero apenas alguna gran estructura constructiva pétrea todavía sin estudios en profundidad (Espadas Pavón et al. 1987; Rojas Rodríguez-Malo 1987; Jiménez Guijarro 1998: 42). Pese a la abundancia de recintos de fosos (Delibes de Castro et al. 2014), la Meseta Norte, sólo había deparado tres lugares amurallados de época calcolítica: El Alto del Quemado (Narrillos del Álamo, Ávila) (López Plaza 1994), El Pedroso (San Martín del Pedroso, Zamora)

* La intervención arqueológica cuyos resultados aquí se presentan han sido financiados por la Consejería de Cultura y Turismo de la Junta de Castilla y León, proyecto "Intervención arqueológica en el yacimiento campaniforme de Pico de la Mora (Peñafiel, Valladolid)" (B2016/004730).

a Dpto. de Prehistoria, Arqueología, Antropología Social y Ciencias y Técnicas Historiográficas. Universidad de Valladolid. Pza. del Campus s/n. 47011 Valladolid. Correo e.: rodrigovillalobosgarcia@gmail.com https://orcid.org/0000-0002-9064-1295

b Dpto. de Historia, Geografía y Comunicación. Universidad de Burgos. Pza. Comendadores s/n (Hospital Militar). 09001 Burgos. Correo e.: jrmarcos@ubu.es https://orcid.org/0000-0002-5136-5312

Recibido 14-II-2017; aceptado 17-VI-2017. 
(Delibes de Castro 1995) y el todavía inédito El Pozuelo (Miño de Medinaceli, Soria) (Rojo Guerra et al. 2008: 322). Estos tres enclaves se distribuyen por la periferia montañosa occidental y meridional de la región. El Pico de la Mora (Peñafiel, Valladolid) ocupa un ámbito bien distinto, el de las comarcas sedimentarias del Duero Medio. Su reciente excavación ha servido para confirmar su condición de asentamiento amurallado del Calcolítico Inicial.

\section{RESULTADOS DE LOS TRABAJOS}

\subsection{Características generales del yacimiento}

El Pico de la Mora (Peñafiel, Valladolid) se ubica en el extremo de un espigón de páramo en las coordenadas UTM 407.575, 4.601.500 (x, y; ETRS89 30N). Uno de nosotros (Rodríguez Marcos) lo descubrió en 1987 durante un estudio del poblamiento prehistórico de la Ribera del Duero vallisoletana. Un galbo cerámico con decoración incisa de estilo Ciempozuelos permitió adscribirlo al Calcolítico Campaniforme o Final. En 1992 una serie de fotografías aéreas revelaron una estructura estrecha y alargada. Su disposición ciñendo el borde septentrional del yacimiento fue interpretada como una posible muralla que habría cerrado el extremo más desprotegido del lugar (Rodríguez Marcos y Moral del Hoyo 2007; Rodríguez Marcos 2008). Para comprobar si efectivamente lo era y, al tiempo, si era coetánea a la cronología asignada en primera instan- cia al yacimiento, en el verano de 2016 realizamos una pequeña intervención arqueológica financiada por la Junta de Castilla y León.

El espigón domina desde una altura relativa de unos $80 \mathrm{~m}$ el estrecho valle del Duratón en un tramo próximo a su desembocadura en el Duero. Esta auténtica atalaya natural se proyecta sobre la margen derecha del río, flanqueada por los barrancos del Sauguillo al norte y de la Mora al sur (Fig. 1). La distribución en superficie de los materiales no supera la 0,5 ha y se localiza en el extremo suroccidental de la plataforma. Dicha área se ve circunvalada por la construcción, que se extiende del extremo noroccidental al suroriental del espigón a lo largo de unos $100 \mathrm{~m}$. En el terreno, la construcción se identifica como una alineación de cascotes amontonados de unos 2-3 $\mathrm{m}$ de anchura que, en algunos puntos, llega a levantar hasta $40 \mathrm{~cm}$ respecto al nivel circundante. $\mathrm{Al}$ nordeste y al sudoeste de la misma abundan los cantos calizos dispersos por el suelo. Como desaparecen a unos $8 \mathrm{~m}$ de distancia creemos que probablemente son bloques caidos de la construcción. Además en el sector noroccidental de la construcción afloran en superficie varios bloques calizos cuyas dimensiones oscilan entre 0,5 y $1 \mathrm{~m}$ y se alinean como un paramento exterior e interior de la misma (Fig. 2).

\subsection{La excavación de la muralla}

El Sondeo 1 era una trinchera de $5 \times 1 \mathrm{~m}$ orientada de forma perpendicular al trazado de la muralla, interesando

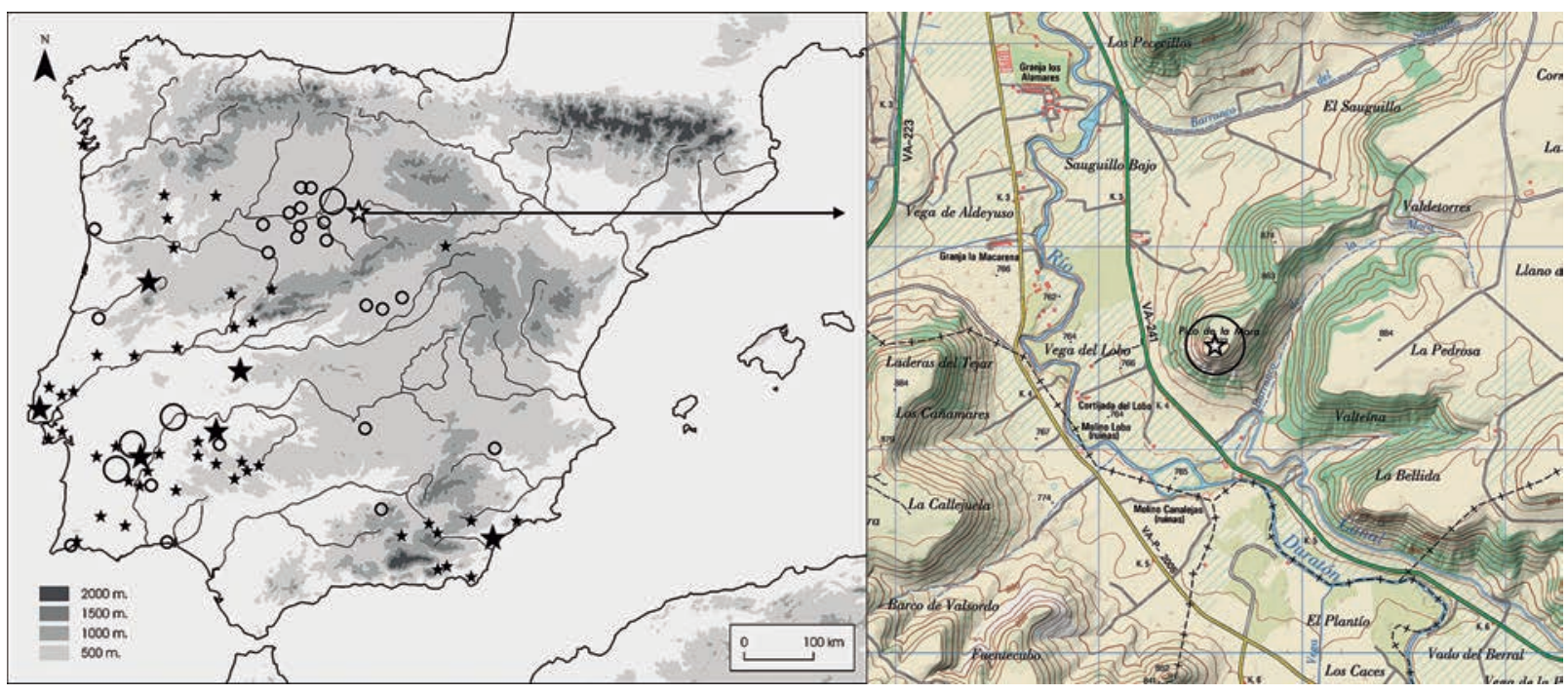

Fig. 1. Localización de El Pico de la Mora (Peñafiel, Valladolid) en la Península Ibérica y su entorno inmediato (Hoja 374-3 Mapa Topográfico Nacional 1994-2017 CC-BY 4.0 Instituto Geográfico Nacional) (en color en la edición electrónica). Distribución de los asentamientos amurallados $(\star)$ y recintos fosados ( $)$ del Calcolítico peninsular citados en el texto. El tamaño de los símbolos indica la concentración de yacimientos.

Trab. Prehist., 75 , N. ${ }^{\circ}$ 1, enero-junio 2018, pp. 155-162, ISSN: 0082-5638

https://doi.org/10.3989/tp.2018.12209 

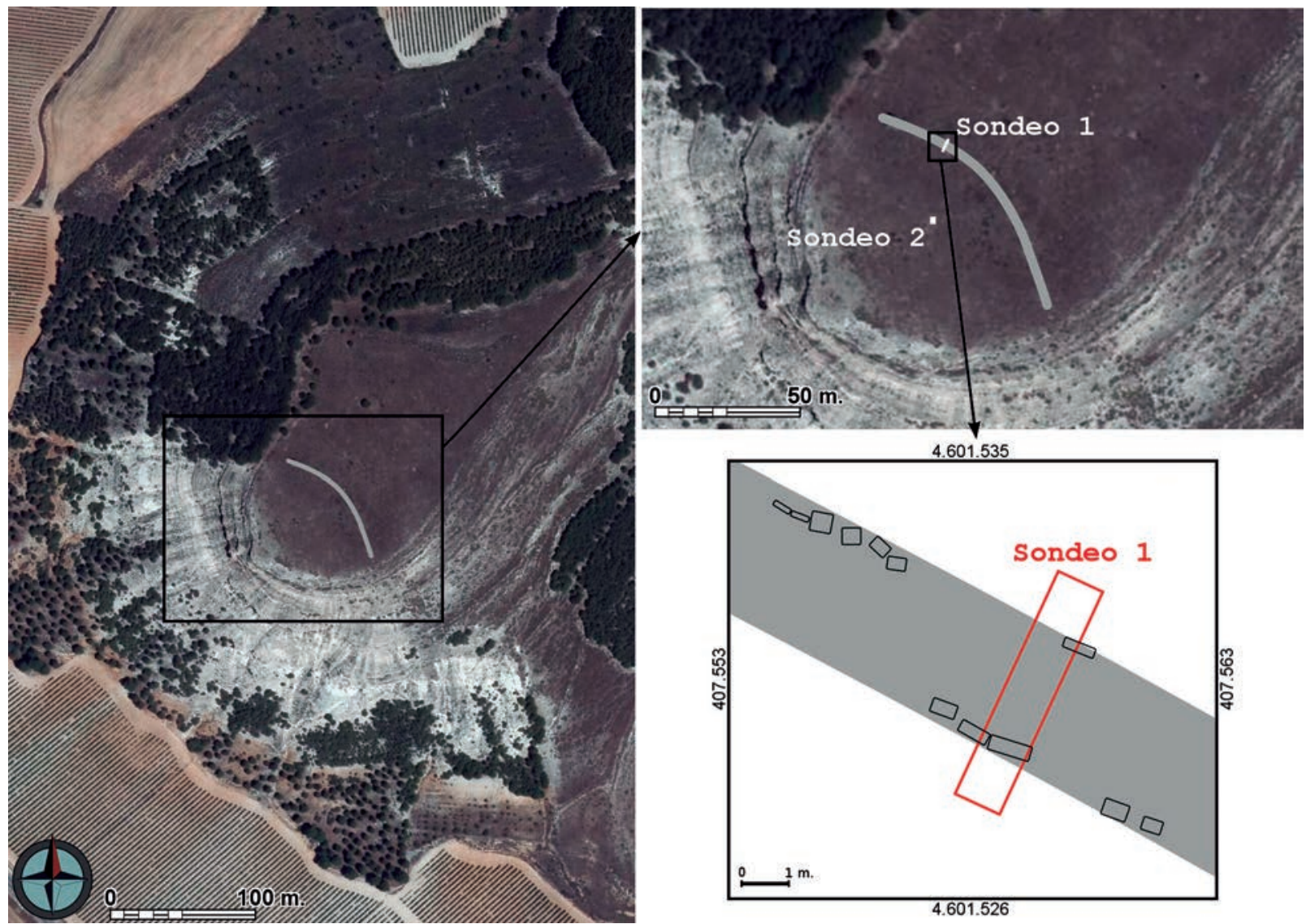

Fig. 2. Localización de la muralla de El Pico de la Mora (Peñafiel, Valladolid) (Hoja 374_1-3 vuelo 2014 PNOACInstituto Geográfico NacionalJunta de Castilla y León). Sobre ella se han ubicado los dos sondeos realizados. El plano detalla los bloques conformantes de los paramentos (rectángulos de línea negra) de la muralla (coordenadas UTM ETRS89 30N) en el Sondeo 1 (en color en la edición electrónica).

tanto a la construcción como a su entorno inmediato. En ella se ha identificado una secuencia constructiva relativamente compleja. Sobre el nivel geológico de calizas del páramo (GEO) y el paleosuelo prehistórico (UE 107) se dispuso un basamento formado por varias losas de piedra caliza (UE 106). Encima se colocaron los dos paramentos de bloques de caliza asentados sobre una de sus caras laterales (UUEE 108 y 110). Las dimensiones del mayor son $30 \times 75 \times 60 \mathrm{~cm}$. Ambos paramentos dis$\tan$ unos 2,75 m. Entre ellos se introdujo el relleno de la muralla (UE 102): una amalgama de cantos calizos de hasta $30 \mathrm{~cm}$ de diámetro máximo, un par de bloques de mayor tamaño y tierra. La altura máxima conservada llega a $60 \mathrm{~cm}$ desde la base (Fig. 3). La presencia de abundantes carbones en las cotas más bajas de este relleno nos sugiere que su estructura interna contase en un primer momento con un armazón de madera. Desconocemos si en un momento anterior, coetáneo o posterior a la conformación del relleno, pero necesariamente

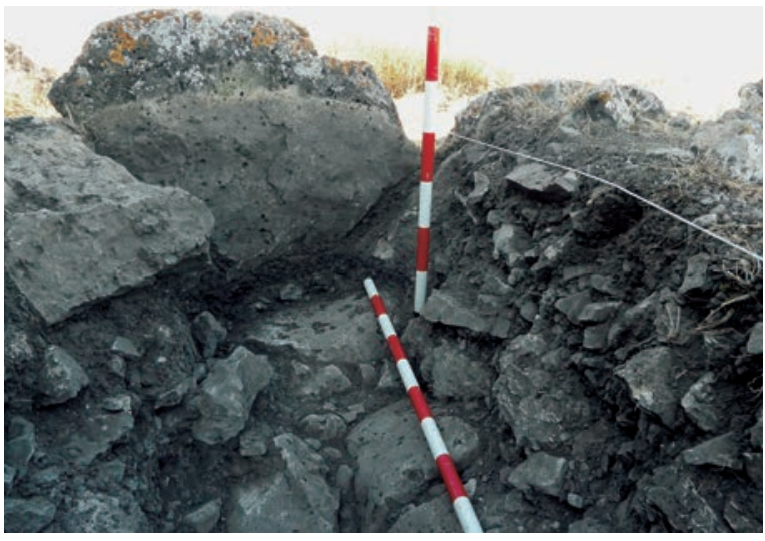

Fig. 3. Sondeo 1 excavado en la muralla de El Pico de la Mora (Peñafiel, Valladolid). Obsérvese el basamento de losas UE 106 (debajo), los bloques del paramento sur UE 108 (de frente) y el relleno de la muralla UE 102 (perfil sureste-izquierda y noroeste-derecha) (en color en la edición electrónica). 
posterior a la colocación del lienzo interior, se dispuso una muy compacta amalgama de cantos calizos de $c a$. $15 \mathrm{~cm}$ diámetro (UE 105), apoyada en este lienzo y extendida hacia el interior del poblado. Su superficie superior buzaba según se alejaba del lienzo mientras que la inferior se apoyaba directamente en el paleosuelo. Dada su elevada compacidad y su orientación lo interpretamos como un contrafuerte interior destinado resistir los empujes de la muralla y evitar así su derrumbe hacia el interior del asentamiento (Fig. 4).

Diversos materiales arqueológicos prehistóricos se han hallado en los rellenos de la muralla y del contrafuerte. En la primera, además de los ya mencionados carbones —uno de ellos datado (véase punto 2.4)-, se recuperaron una treintena de fragmentos de cerámica a mano, una pequeña lámina de sílex gris sin retocar de sección trapezoidal (Fig. 5: 5) y pellas muy pequeñas de barro anaranjado. En las cotas inferiores del contrafuer- te, ya casi en contacto con el paleosuelo, apareció una decena de galbos de cerámica a mano. Cuatro pertenecen al mismo vaso de forma derivada de la esfera (Fig. 5: 4).

\subsection{La excavación del asentamiento}

El sondeo en la muralla se complementó con otro en el área del presunto asentamiento de $6 \mathrm{~m}^{2}$ (Fig. 2). Por desgracia el lugar se encuentra muy erosionado y la potencia del depósito no superó los $15 \mathrm{~cm}$ hasta las calizas geológicas del páramo. No se pudieron identificar estructuras propias de una actividad doméstica - cimientos de cabaña, hoyos de almacenaje, hogares, etc.- pero se puede intuir de forma indirecta de la recuperación de pequeñas pellas de barro crudo anaranjado que muy bien pudieron proceder de alguna cabaña.

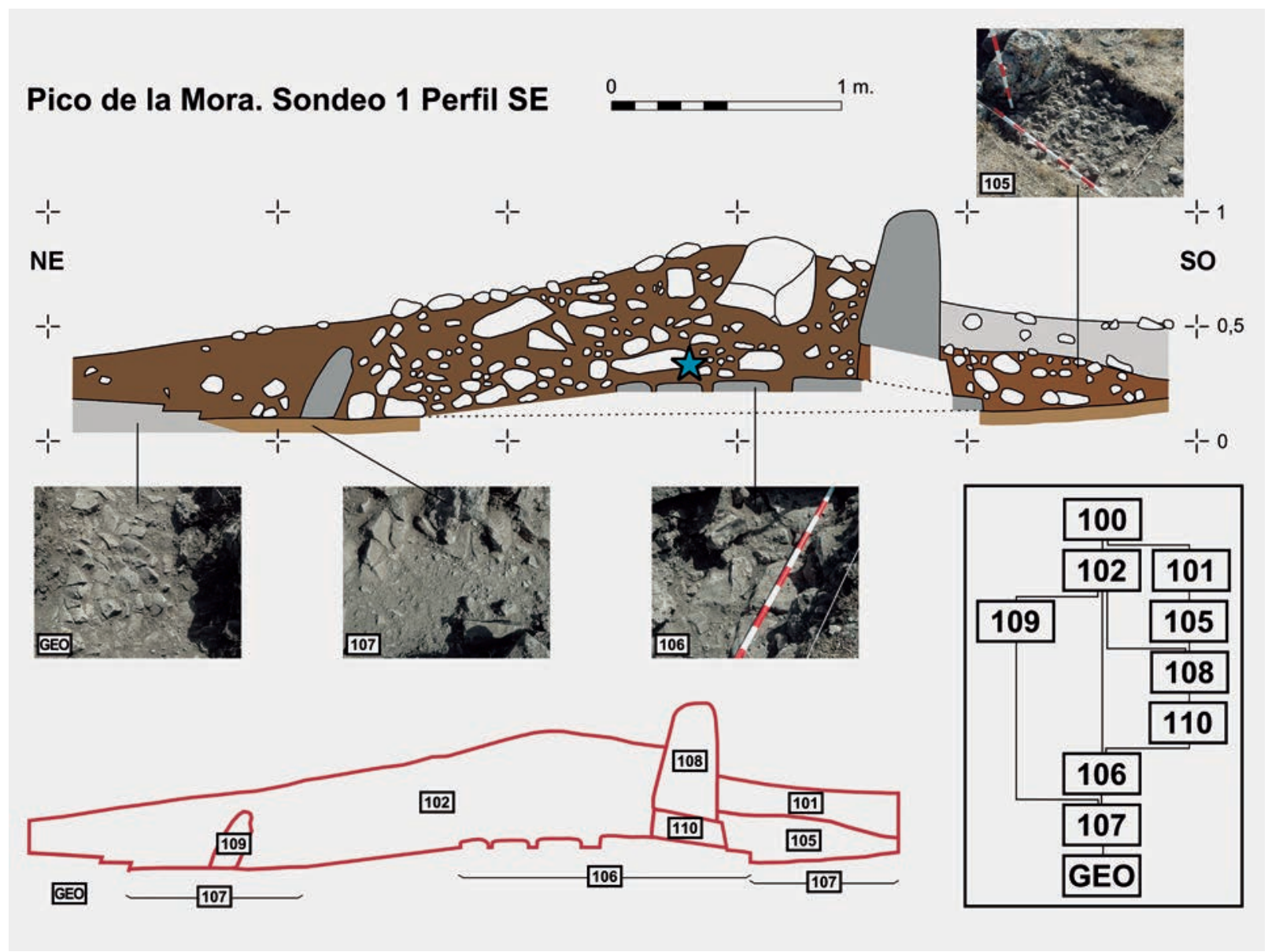

Fig. 4. Perfil SE del Sondeo 1 acompañado de fotografías de las superficies donde se sustentó la muralla (GEO, UE 107, UE 106) y del contrafuerte (UE 105), así como de las relaciones estratigráficas de sus elementos conformantes. La $\star$ de la UE 102 localiza la muestra de madera carbonizada datada por radiocarbono (en color en la edición electrónica). 
Los artefactos aparecidos fueron media docena de galbos de cerámica a mano y, lo más significativo, una veintena de restos de sílex blanquecino, gris, naranja y azulado, entre ellos hay un pequeño núcleo de extracción de pequeñas láminas y una lasca con retoque bifacial denticulado con el denominado "lustre de cereal", probablemente usada como instrumento agrícola (Fig. 5: 6). Además de la superficie del Sondeo 2 procede un fragmento de fusayola de barro crudo (Fig. 5: 2) y un galbo de cerámica a mano con una carena (Fig. 5: 1).

\subsection{El Pico de la Mora: cronología de un asentamiento calcolítico amurallado}

La intervención cumplió con las expectativas originales y, además, ha ofrecido una interesante información adicional. Podemos defender que la muralla prehistórica fue una construcción relativamente compleja - basamento, lienzos, posible estructura lígnea, contrafuerte-, en especial si consideramos que las comunidades tardoneolíticas normeseteñas carecen de tradición poliorcética. La datación radiocarbónica calibrada (Oxcal 4.2.3 IntCal13 2б: 2878-2631 cal a. C.) (Tab. 1) de uno de los fragmentos de maderas carbonizadas (Fig. 4), que interpretamos como constituyentes de la estructura del relleno, ubica el momento específico de construcción de la muralla en el primer tercio del III milenio cal a. C., en pleno Calcolítico Inicial o Precampaniforme.

En el espacio cercado por esta muralla del Calcolítico Inicial, antes o en el momento inmediato de su construcción, se desarrollaron actividades que generaron residuos cerámicos como los abundantes galbos rodados presentes en el relleno o las cerámicas más enteras recuperadas bajo el contrafuerte. Éstas últimas son las mejor conservadas y las de mayor tamaño identificadas en el yacimiento, caso de la vasija de forma derivada de la esfera cuyo diámetro estimamos en 0,5 m (Fig. 5: 4).

Las prácticas de manufactura lítica documentadas en el Sondeo 2 -núcleo y abundantes restos de talla de sílex-, así como las de probable actividad textil -el fragmento de fusayola recuperado en superficie - no son impropias de este Calcolítico Inicial pero tampoco de otros periodos prehistóricos. De hecho el fragmento cerámico con decoración tipo Ciempozuelos recogido en la prospección superficial de los años 1980 (Fig. 5: 3) habla de una ocupación coetánea a la del cercano asentamiento, también en altura, de Pico del Castro (Quintanilla de Arriba, Valladolid), que el radiocarbono fecha en ca. 2400-1960 cal a. C. (Rodríguez Marcos y Moral del Hoyo 2007). El galbo carenado recuperado en esta campaña de 2016 asimismo en superficie (Fig. 5: 1) refuerza esta atribución cronológica, pues formas de este tipo aparecen en la fase II del yacimiento campaniforme de Molino Sanchón II

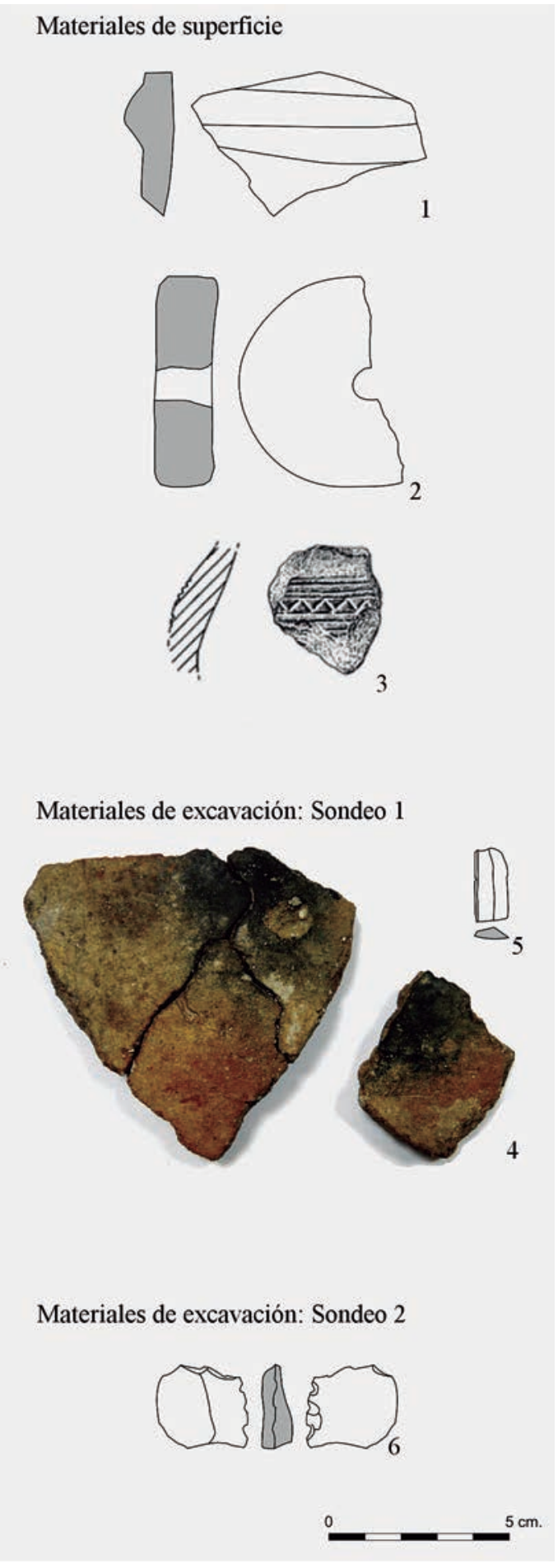

Fig. 5. El Pico de la Mora (Peñafiel, Valladolid): 1. galbo carenado de cerámica a mano; 2 . fusayola de barro crudo; 3 . galbo cerámico con decoración incisa de estilo Ciempozuelos; 4. galbos de cerámica a mano del mismos vaso (en color en la edición electrónica). Sílex 5. lámina; 6. lasca con retoque denticulado y "lustre de cereal". 


\begin{tabular}{|c|c|c|c|c|c|c|}
\hline Contexto & Laboratorio & Método & N $^{\mathbf{0}}$ muestra & Fecha BP & \pm & Material \\
\hline $\begin{array}{l}\text { Relleno } \\
\text { muralla }\end{array}$ & Poz & AMS & 85649 & 4155 & 30 & $\begin{array}{c}\text { Madera } \\
\text { carbonizada }\end{array}$ \\
\hline
\end{tabular}

Tab. 1. Datación radiocarbónica de la muralla de El Pico de la Mora (Peñafiel, Valladolid).

(Villafáfila, Zamora), fechado en ca. 2300-2050 cal a. C. (Abarquero Moras et al. 2012: figs. 193.6 y 196.6).

Por otro lado, cabe destacar la ausencia de rasgos en la cerámica del Pico de la Mora como las vasijas cerradas con cuello, las de impresiones en el labio o los vasos ornados con mamelones y/o cordones dígito/ ungulados. Por ello, consideramos que no hubo ocupación en los momentos posteriores al Campaniforme, ya en el Bronce Antiguo-Pleno (Rodríguez Marcos 2008: 274-290), también llamado en esta región "Horizonte Parpantique” (Fernández Moreno 2011: 95-114).

Caben dos posibilidades, o bien que El Pico de la Mora fuera habitado en dos momentos distintos del III milenio cal a. C. - a su inicio, cuando se erigió la muralla, y tras un hiato, en los últimos siglos del mismo- o bien que hubiera una ocupación continua entre el momento de amurallamiento y las evidencias más tardías de actividad campaniforme. A priori, y a falta de otra información que pudiera esclarecer este asunto, nos decantamos por la segunda opción. Si la construcción se hizo en un único evento - puesto que no parece segmentada ni compuesta por varias líneas de muralla - como el trabajo se estima en, al menos, 6.000 días/persona (Villalobos García 2016b) la inversión habría sido demasiado grande para que un pequeño grupo - como el que se presupone ocuparía un asentamiento de 0,5 ha- la hubiera abandonado al poco de su erección.

El Pico de la Mora, según su datación absoluta ca. 2900-2650 cal a. C., es el asentamiento amurallado más antiguo de la Meseta Norte, en plena consonancia con las que aportan otras obras monumentales como son los recintos de fosos —el foso 1 de El Casetón de la Era (Villalba de los Alcores, Valladolid) tiene una fecha de c. 2850-2500 cal a. C. (Delibes de Castro et al. 2009). En estos primeros siglos del Calcolítico en la región, se han documentado grandes cambios en los sistemas poblacionales (Delibes de Castro et al. 1997), agroganaderos (Delibes de Castro 2011) y artesanales (Delibes de Castro et al. 2006; Fábregas Valcarce y Rodríguez Rellán 2008; Villalobos García y Odriozola 2016). Por tanto, no sería descabellado interpretar el fenómeno del amurallamiento que vemos en El Pico de la Mora como parte integrante de un proceso generalizado de transformaciones que probablemente incluyeran profundas reorganizaciones en las formas de apropiación del territorio y en los sistemas de organización social (Villalobos García 2016a).

\section{DISCUSIÓN: EL PICO DE LA MORA EN EL CONTEXTO DE LOS ASENTAMIENTOS CALCOLÍTICOS FORTIFICADOS DE LA PENÍNSULA IBÉRICA}

La cronología de la muralla de El Pico de la Mora es algo posterior a la de las primeras estructuras de arquitectura de piedra del Suroeste y Sureste peninsular, fechadas a fines del IV milenio cal a. C. (Balsera et al. 2015) pero es equiparable a la de los primeros asentamientos amurallados del Occidente peninsular, tanto en el Centro y Sur del actual Portugal (Gonçalves et al. 2013) como en el Norte del mismo (Jorge 2003; Sanches 2003). Naturalmente la complejidad y entidad de las estructuras meridionales y occidentales no son comparables con las del Pico de la Mora, pero sin duda forman parte de un mismo fenómeno, el de amurallar asentamientos, generalizado en estos momentos en buena parte de la Península Ibérica. La parquedad que, por ahora, ofrece nuestro registro, nos impide debatir si esto tendría una finalidad estrictamente defensiva (Gonçalves et al. 2013) u otros objetivos sociales y/o ceremoniales (Jorge 1994; Fábregas Valcarce 2010: cap. iv; Díaz-del-Río 2011). Si acaso podría apuntarse un posible uso defensivo al trazado de la muralla de El Pico de la Mora, que cierra un perímetro compuesto en su mayor parte por las potentes defensas naturales del borde del páramo (Fig. 2).

Llamamos la atención sobre una circunstancia de la ubicación de El Pico de la Mora en el conjunto de asentamientos fortificados peninsulares: la total ausencia de construcciones de este tipo entre los yacimientos con estructuras domésticas adscribibles al Calcolítico en la región cantábrica y la cuenca del Ebro (e.g., Álvarez Clavijo et al. 1997; Clop García 2005; Sesma Sesma et al. 2009; Ontañón Peredo 2012). Más al norte del sitio amurallado de La Mesa de Montes (Cangas do Morrazo, Pontevedra) (Gorgoso López et al. 2011) no se conocen yacimientos calcolíticos de esta naturaleza. Los límites seguramente sean difusos, pero puede intuirse una línea que desde el Sureste, en el golfo de Mazarrón (Murcia), hasta el Noroeste, en la península del Morrazo (Pontevedra), delimitaría dos regiones: con asentamientos calcolíticos amurallados (área central, meridional y occidental) o sin ellos (tercio nororiental). La primera coincide aproximadamente con la distribución de los recintos fosados, las otras grandes obras colectivas del Calcolítico peninsular

Trab. Prehist., 75, N. ${ }^{\circ}$ 1, enero-junio 2018, pp. 155-162, ISSN: 0082-5638

https://doi.org/10.3989/tp.2018.12209 
(Díaz-del-Río 2003; Márquez Romero y Jiménez Jáimez 2010; Bernabeu Aubán et al. 2012; Delibes de Castro et al. 2014; Valera 2015) (Fig. 1), así como con la de varias redes de circulación de artefactos sociotécnicos como elementos de marfil (Schuhmacher 2012), objetos de caliza (Villalobos García 2013) o adornos de variscita zamorana (Villalobos García y Odriozola 2016).

\section{CONCLUSIONES}

La modesta intervención realizada en El Pico de la Mora ha revelado ciertos aspectos relevantes. La construcción de una muralla de unos $100 \mathrm{~m}$ de longitud, erigida a comienzos del Calcolítico (ca. 2900-2650 cal a. C.), junto con el abrupto desnivel del borde del páramo, cierra un espacio de unas 0,5 ha ocupado durante esta época para distintas actividades de carácter doméstico. El contexto histórico de este evento fue el de un proceso de transformaciones - mayor grado de sedentarización poblacional, intensificación económica y desigualdades sociales - que se documentan en ciertas zonas de la Meseta Norte, así como en buena parte de la Península Ibérica, con distinta intensidad en cada caso. La distribución a escala peninsular de asentamientos calcolíticos con grandes elementos arquitectónicos, unida a la presencia de redes de circulación de determinados artefactos sociotécnicos, hace de nuestro Pico de la Mora un ejemplar enclavado en el extremo nororiental de este fenómeno. Quizás fuera una zona de fricción entre dos inercias diferenciadas por sus dinámicas sociales calcolíticas que, aunque internamente puedan parecer heterogéneas, a gran escala muestran la tendencia a una mayor "complejidad" al Sur y a más "resistencia" al Norte.

\section{AGRADECIMIENTOS}

En los trabajos de excavación de El Pico de la Mora han colaborado Xavier Bayer, Angélica Santa Cruz, Eduardo Martínez, Héctor Fonseca, Sandra Vázquez y Silvia Serrador. Conste aquí nuestro agradecimiento hacia ellos.

\section{BIBLIOGRAFÍA}

Abarquero Moras, F. J.; Guerra Doce, E.; Delibes de Castro, G.; Palomino Lázaro, Á. L. y Val Recio, J. 2012: Arqueología de la sal en las Lagunas de Villafáfila (Zamora): investigaciones sobre los cocederos prehistóricos. Monografías Arqueología en Castilla y León 9, Junta de Castilla y León. Valladolid.

Álvarez Clavijo, P.; Cenizeros Herrero, J. e Ilarraza Tejada, J. A. 1997: "Nuevos datos para la definición del Calcolítico en el Valle AltoMedio del Ebro". En R. de Balbín y P. Bueno (eds.): II Congreso de Arqueología Peninsular (Zamora 1996) II. Neolítico, Calcolítico y Bronce: 291-300. Zamora.
Balsera, V.; Bernabeu Aubán, J.; Costa Caramé, M. E.; Díaz-del-Río, P.; García Sanjuán, L. y Pardo, S. 2015: "The radiocarbon chronology of Southern Spain's Late Prehistory (5600-1000 cal BCE): a comparative review". Oxford Journal of Archaeology 34 (2): 139-156.

Bernabeu Aubán, J.; Orozco Köhler, T. y Díez Castillo, A. 2012: "Mas d'Is y las construcciones con fosos del VI al II milenio cal a. C". Marq arqueología y museos 5: 53-72.

Chapman, R. 2008: "Producing inequalities: regional sequences in Later Prehistoric Southern Spain”. Journal of World Prehistory 21 (3-4): 195-260.

Clop García, X. 2005: “La 'cuestión campaniforme' en el Noroeste de la Península Ibérica”. En M. Á. Rojo, R. Garrido Pena e Í. García (eds.): El Campaniforme en la Península Ibérica y su contexto europeo. Universidad de Valladolid. Valladolid: 297-320.

Delibes de Castro, G. 1995: "Neolítico y Edad del Bronce". En Historia de Zamora, I De los orígenes al final del medievo. Instituto de Estudios Zamoranos Florián de Ocampo. Zamora: 47-100.

Delibes de Castro, G. 2011: El pan y la sal. La vida campesina en el Valle Medio del Duero hace cinco mil años. Real Academia de Bellas Artes de la Purísima Concepción. Valladolid.

Delibes de Castro, G.; Benet Jordana, N.; Pérez Martín, R. y Zapatero Magdaleno, P. 1997: "De la tumba dolménica como referente territorial, al poblado estable: notas sobre el hábitat y las formas de vida de las comunidades megalíticas de la Submeseta Norte". En A. A. Rodríguez Casal (ed.): O neolitico atlántico e as orixes do megalitismo. Universidad de Santiago de Compostela. Santiago de Compostela: 779-808.

Delibes de Castro, G.; Crespo Díez, M.; Fernández Manzano, J.; Herrán Martínez, J. I. y Rodríguez Marcos, J. A. 2009: “¿Stonehenge en Tierra de Campos? Excavaciones en el yacimiento de la Edad del Cobre de El Casetón de la Era (Villalba de los Alcores, Valladolid)". En E. Wattenberg (ed.): Conocer Valladolid. II Curso de Patrimonio Cultural. Real Academia de Bellas Artes de la Purísima Concepción. Valladolid: 15-33.

Delibes de Castro, G.; Fernández Manzano, J. y Herrán Martínez, J. I. 2006: "La metalurgia del inicio de la Edad del Cobre en la Submeseta Norte Española: Los desafíos del aprovisionamiento". Sautuola 12: 127-134.

Delibes de Castro, G.; García García, M.; Olmo Martín, J. y Santiago Pardo, J. 2014: Los recintos de fosos calcolíticos del valle medio del Duero: Arqueología Aérea y Espacial. Universidad de Valladolid. Valladolid.

Díaz-del-Río, P. 2003: "Recintos de fosos del III milenio AC en la Meseta peninsular". Trabajos de Prehistoria 60 (2): 61-78. https://doi.org/10.3989/tp.2003.v60.i2.81

Díaz-del-Río, P. 2011: "Labor in the Making of the Iberian Copper Age Lineages". En K. T. Lillios (ed.): Comparative Archaeologies. The American Southwest (AD 900-1600) and the Iberian Peninsula (3000$1500 B C$ ). Oxbow Books. Oxford: 37-56.

Díaz-del-Río, P. y García Sanjuán, L. (eds.) 2006: Social Inequality in Iberian Late Prehistory. Archaeopress. Oxford.

Espadas Pavon, J. J.; Poyato Holgado, C. y Caballero Klink, A. 1987: “Memoria preliminar de las excavaciones del yacimiento calcolítico de 'El Castellón' (Villanueva de los Infantes, Ciudad Real)”. Oretum 3: 40-78.

Fábregas Valcarce, R. 2010: Os petróglifos e o seu contexto: un exemplo da Galiza meridional. Instituto de Estudios Vigueses. Vigo.

Fábregas Valcarce, R. y Rodríguez Rellán, C. 2008: “Gestión del cuarzo y la pizarra en el Calcolítico peninsular: el 'santuario' de El Pedroso (Trabazos de Aliste, Zamora)". Trabajos de Prehistoria 65 (1): 125-142. https://doi.org/10.3989/tp.2008.v65.11.139

Fernández Moreno, J. J. 2011: "Algunas reflexiones sobre la ocupación del territorio en los momentos iniciales de la Edad del Bronce en el Alto Duero". En P. Bueno, A. Gilman y F. J. Sánchez-Palencia (eds.): Arqueología, sociedad, territorio y paisaje. Estudios sobre Prehistoria reciente, Protohistoria y transición al mundo romano en homenaje a $M^{a}$ Dolores Fernández-Posse. Bibliotheca Praehistorica Hispana XXVIII, CSIC. Madrid: 95-114

Gonçalves, V. S.; Sousa, A. C. y Costeira, C. 2013: "Walls, gates and towers. Fortified settlements in the South and Centre of Portugal: some notes about violence and walls in the 3rd millennium BCE". Cuadernos de Prehistoria y Arqueología de la Universidad de Granada 23: 35-97. 
Gorgoso López, L.; Fábregas Valcarce, R. y Acuña Piñeiro, Á. 2011: "Desmontando La Mesa de Montes (Cangas do Morrazo, Pontevedra). Aproximación arqueohistórica a un asentamiento calcolítico en altura". Zephyrus 67: 111-128.

Jiménez Guijarro, J. 1998: "La neolitización de la Cuenca Alta del Tajo. Nuevas propuestas interpretativas para el Neolítico de la Meseta". Complutum 9: 27-47.

Jorge, S. O. 1994: "Colónias, Fortificações, Lugares Monumentalizados. Trajectória das Concepções sobre um tema do Calcolítico Peninsular". Revista da Faculdade de Letras. Porto. História II (11): 447-546.

Jorge, S. O. 2003: "Pensar o espaço da Pré-história Recente: A propósito dos recintos murados de Península Ibérica”. En S. O. Jorge (ed.): Recintos murados da Pré-História Recente. Faculdade de Letras da Universidade do Porto. Oporto: 13-50.

Lillios, K. T. (ed.) 1995: The origins of complex societies in Late Prehistoric Iberia. International Monographs in Prehistory. Ann Arbor.

López Plaza, S. 1994: "El Alto del Quemado, poblado calcolítico fortificado en el SO de la Meseta Norte Española". Trabalhos de Arqueología da Estudo Arqueológico da Bacia do Mondego 2: 201-214.

Márquez Romero, J. E. y Jiménez Jáimez, V. J. 2010: Recintos de Fosos. Genealogía y significado de una tradición en la Prehistoria del suroeste de la Península Ibérica (IV-III milenios AC). Universidad de Málaga. Málaga.

Ontañón Peredo, R. 2012: "Social Dynamics in the Recent Prehistory of Northern Iberia. Examining the Margins of the Mediterranean Regions". En M. Cruz Berrocal, L. García Sanjuán y A. Gilman (eds.): The Prehistory of Iberia. Debating Early Social Stratification and the State. Routledge. Nueva York: 203-230.

Rodríguez Marcos, J. A. 2008: Estudio secuencial de la Edad del Bronce en la Ribera del Duero (provincia de Valladolid). Monografías Arqueología en Castilla y León 7, Junta de Castilla y León. Valladolid.

Rodríguez Marcos, J. A. y Moral del Hoyo, S. 2007: "Algunas notas acerca del poblamiento campaniforme en el sector vallisoletano de la Ribera del Duero". Zephyrus 60: 181-194.

Rojas Rodríguez-Malo, J. M. 1987: "La Huerta del Diablo: un posible asentamiento calcolítico con muralla circular". Trabajos de Prehistoria 44: 271-282.

Rojo Guerra, M. Á.; Garrido Pena, R. y García Martínez de Lagrán, Í. 2008: "Everyday routines or special ritual events? Bell Beakers in domestic contexts of Inner Iberia”. En M. Baioni, V. Leonini, D. Lo Vetro, F. Martini, R. Poggiani y L. Sarti (eds.): Bell Beaker in everyday life. Museo Fiorentino di Preistoria Paolo Graziosi. Florencia: 321-326.

Sanches, M. de J. 2003: "O Crasto de Palheiros (Murça, Trás-os-Montes). Interpretação dum sitio nos alvores da metalurgia calcolítica”. En J. Fernández Manzano y J. I. Herrán (eds.): Mineros y fundidores en el inicio de la Edad de los Metales. El Midi francés y el Norte de la península ibérica. Caja España. León: 99-119.

Schuhmacher, T. X. 2012: "El marfil en España desde el Calcolítico al Bronce Antiguo". En A. Banerjee, J. A. López Padilla y T. X. Schuhmacher (eds.): Elfenbeinstudien faszikel 1. Marfiles y elefantes en la Península Ibérica y el Mediterráneo Occidental. Verlag Philipp von Zabern. Mainz: 45-68.

Sesma Sesma, J.; López Quintana, J. C.; Mújika Alustiza, J. A.; Rodanés Vicente, J. M. y Vegas Aramburu, J. I. 2009: "El periodo calcolíticoEdad del Bronce en el Cantábrico oriental y su territorio". En A. Llanos Ortiz (ed.): Actas del Congreso Internacional medio siglo de Arqueología en el Cantábrico oriental y su entorno (Vitoria 2007): 115-200. Vitoria

Siret, E. y Siret, L. 1890: Las Primeras Edades del Metal en el sudeste de España. Resultados obtenidos en las excavaciones hechas por los autores desde 1881 á 1887. Barcelona.

Valera, A. C. 2015: "Social change in the late $3^{\text {rd }}$ millennium BC in Portugal: the twilight of enclosures". En H. Meller, H. W. Arz, R. Jung y R. Risch (eds.): 2200 BC - Ein Klimasturz als Ursache für den Zerfall der Alten Welt? Band I. Erscheinungsjahr. Halle: 409-427.

Villalobos García, R. 2013: "Artefactos singulares de filiación meridional en el Calcolítico de la Meseta Norte española: un vaso calcáreo procedente de El Fonsario (Villafáfila, Zamora)". Zephyrus 71: 131-148.

Villalobos García, R. 2016a: Análisis de las transformaciones sociales en la Prehistoria Reciente de la Meseta Norte española (milenios VI-III cal a. C.). Universidad de Valladolid. Valladolid.

Villalobos García, R. 2016b: "Una aproximación cuantitativa al trabajo destinado a la arquitectura monumental en la Prehistoria Reciente de la Meseta Norte Española”. Spal 25: 43-66.

Villalobos García, R. y Odriozola, C. P. 2016: "Organizing the production of variscite personal ornaments in Later Prehistoric Iberia: the mines of Aliste and the production sites of Quiruelas de Vidriales (Zamora, Spain)". European Journal of Archaeology 19 (4): 631-651.

Trab. Prehist., 75, N. ${ }^{\circ}$ 1, enero-junio 2018, pp. 155-162, ISSN: 0082-5638

https://doi.org/10.3989/tp.2018.12209 